\title{
Brittle or Quasi-Brittle Fracture of Engineering Materials: Recent Developments and New Challenges
}

\author{
F. Berto, ${ }^{1}$ M. Elices, ${ }^{2}$ M. R. Ayatollahi, ${ }^{3}$ S. V. Panin, ${ }^{4}$ and K. Tserpes ${ }^{5}$ \\ ${ }^{1}$ Department of Management and Engineering, University of Padova, Stradella San Nicola 3, 36100 Vicenza, Italy \\ ${ }^{2}$ Departamento de Ciencia de Materiales, Universidad Politécnica de Madrid, \\ E. T. S. de Ingenieros de Caminos Canales y Puertos C/ Profesor Aranguren s/n, 28040 Madrid, Spain \\ ${ }^{3}$ Fatigue and Fracture Research Laboratory, Center of Excellence in Experimental Solid Mechanics and Dynamics, \\ School of Mechanical Engineering, Iran University of Science and Technology, Narmak, Tehran 16846, Iran \\ ${ }^{4}$ Department of Mechanical Engineering \& Aeronautics, Institute of Strength Physics and Material Science, \\ Siberian Branch of Russian Academy of Sciences, Tomsk 634021, Russia \\ ${ }^{5}$ Laboratory of Technology \& Strength of Materials (LTSM), Department of Mechanical Engineering \& Aeronautics, \\ University of Patras, 26500 Patras, Greece \\ Correspondence should be addressed to F. Berto; berto@gest.unipd.it
}

Received 17 March 2014; Accepted 17 March 2014; Published 22 April 2014

Copyright (C) 2014 F. Berto et al. This is an open access article distributed under the Creative Commons Attribution License, which permits unrestricted use, distribution, and reproduction in any medium, provided the original work is properly cited.

Brittle or quasi-brittle fracture of engineering materials is a wide field of research, which involves many researchers devoted to investigating different aspects of the mechanics and physics of fracture. Materials usually treated include metal alloys, polymers, composites, rocks, and ceramics.

Brittle failure is not a phenomenon limited only to static loadings. It may also be related to the fatigue and failure under repeated loading cycles (mechanical or thermal). The material damage process is usually very complex because it involves the combined effects of loading, size and geometry, temperature, and environment. The understanding of the phenomena tied to the dissipation of energy in various forms and the identification of microscopic properties and their interactions with macroscopic variables are the actual challenging topics. The fracture mechanics science emphasizes material characterization techniques and translation of specimen data to design.

The present special issue contains original research and review articles that seek to define possible criteria against brittle and quasi-brittle failure and to present or discuss new sets of experimental data in combination with fracture assessment. Among the areas emphasized in the SI are case histories, material selection and structure design, sample calculations of practical design problems, material characterization procedures, fatigue crack growth and corrosion, nondestructive testing and inspection, structural failure and ageing, failure prevention methodologies, and maintenance and repair.

The papers submitted by the authors have been subjected to the normal journal peer-review process. Altogether the special issue contains 13 papers.

In the paper entitled "Effect of silicon addition on hightemperature solid particle erosion-wear behaviour of mullite$\mathrm{SiC}$ composite refractories prepared by nitriding reactive," the effects of silicon powder addition and erosion temperature on the erosion-wear resistance of mullite-SiC composite refractories are studied. The work provides the theoretical basis for the development of wear-resistant refractory materials.

In the paper entitled "Average fracture energy for crack propagation in postfire concrete" Wedge-splitting tests of postfire concrete specimens are summarised considering ten temperatures varying from room temperature to $600^{\circ} \mathrm{C}$. The accurate calculation of the fracture energy at different temperatures is carried out in the paper.

In the paper entitled "Al and Si influences on hydrogen embrittlement of carbide-free bainitic steel," a method based 
on the density functional theory is applied to investigate the $\mathrm{Al}$ and $\mathrm{Si}$ influences on the hydrogen embrittlement of carbide-free bainitic steel. The paper shows that hydrogen embrittlement can be reduced by the presence of $\mathrm{Al}$ rather than Si.

In the paper entitled "Preparation, microstructure, and mechanical properties of spinel-corundum-Sialon composite materials from waste fly ash and aluminum dross," a new method is provided to reduce environmental pollution and manufacture low cost high performance refractory materials using the abundant waste materials fly ash and aluminum dross.

The paper entitled "Study on strength and ultrasonic velocity of air-entrained concrete and plain concrete in cold environment" deals with the behavior of ultrasonic velocity and mechanical properties of plain concrete and air-entrained concrete subjected to freeze-thaw cycles. In particular the influences of F-T cycles on ultrasonic velocity and mechanical properties of C30 air-entrained concrete and plain concrete have been investigated. The experimental results can be useful for the design of new concrete structure, maintenance, and life prediction of existing concrete structure such as offshore platform and concrete dock wall.

In the paper entitled "An analytical model for predicting the stress distributions within single-lap adhesively bonded beams," an analytical model for assessing the stress field within single-lap adhesively bonded beams under tension has been developed. By combining the governing equations of each adherent with the joint kinematics, the overall system of governing equations can be obtained assuming plane strain conditions. With suitable boundary conditions, the stress distribution of the adhesive in the longitudinal direction is determined.

The paper entitled "Toughness calculation of postfire normal concrete" deals with fracture tests of postfire normal concrete tested at ten temperatures up to $600^{\circ} \mathrm{C}$. Residual fracture toughness using analytical method is determined at different temperatures.

The paper entitled "A brief review of some local approaches for the failure assessment of brittle and quasi-brittle materials" summarizes some local criteria applicable in presence of cracks and sharp/blunt notches.

The paper entitled "Strain rate dependent ductile-to-brittle transition of graphite platelet reinforced vinyl ester nanocomposites" is aimed at studying the strain rate dependent ductileto-brittle transition of vinyl ester based nanocomposites. In more detail, the fracture behavior of $\mathrm{xGnP}$ (exfoliated graphite nanoplatelets) reinforced with additional CTBN (carboxyl terminated butadiene nitrile) toughened vinyl ester based nanocomposites is extensively studied.

The paper entitled "Simulation of hydraulic fracture in unsaturated soils with high degree of saturation" studies the hydraulic fracture process, considering the couplings of the stress distribution, the fluid flow of the water-air mixture, the compression and dissolution of air, and the element damage evolution. A large number of numerical analyses on hydraulic fracturing in clay with incipient injection slot have been carried out in the paper.
The paper entitled "Computational and simulation analysis of pull-out fiber reinforced concrete" investigates by means of complex numerical analyses the behavior of the reinforced concrete in its three constituents: the concrete matrix, the placed fiber reinforcement polymers (FRP), and resin layer.

The paper entitled "Fatigue properties of layered double hydroxides modified asphalt and its mixture" is devoted to the study of the influence of layered double hydroxides (LDHs) on the fatigue properties of asphalt mixture. A large bulk of experimental data from fatigue tests are summarized in the paper.

The paper entitled "Application of $T_{33}$-stress to predict the lower bound fracture toughness for increasing the test specimen thickness in the transition temperature region" faces the influence of out-of-plane crack tip constraint on the J calculation showing the capability of the elastic T-stress to accurately capture this behavior.

In doing so, a set of papers united by general direction of studies and giving a wide outlook onto fracture processes to take place in various heterogeneous materials and loading conditions are presented. They describe the peculiarities of fracture process in correlation with structure and provide adequate numerical calculation data to estimate stress-strain state evolution and characterize deformation behavior. We hope that the book will be of substantial interest for specialists in fracture mechanics and provide additional insight onto numerous aspects of brittle and quasi-brittle fracture.

\section{Acknowledgment}

We thank the many anonymous reviewers who assisted us in the review process providing useful comments and proposing constructive improvements to the authors. Without their continuous and valuable support also our efforts could have been useless.

F. Berto

M. Elices

M. R. Ayatollahi

S. V. Panin

K. Tserpes 

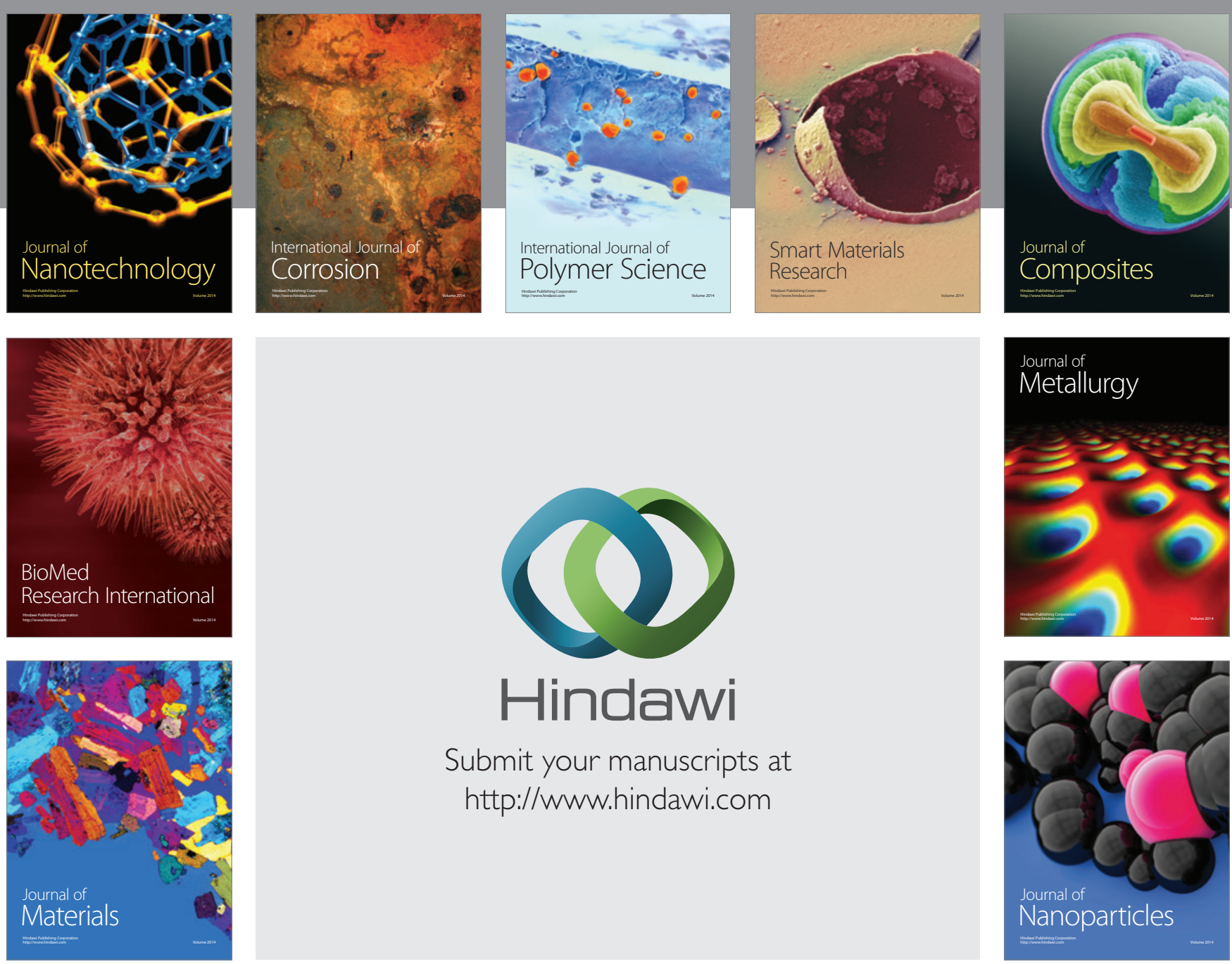

Submit your manuscripts at http://www.hindawi.com
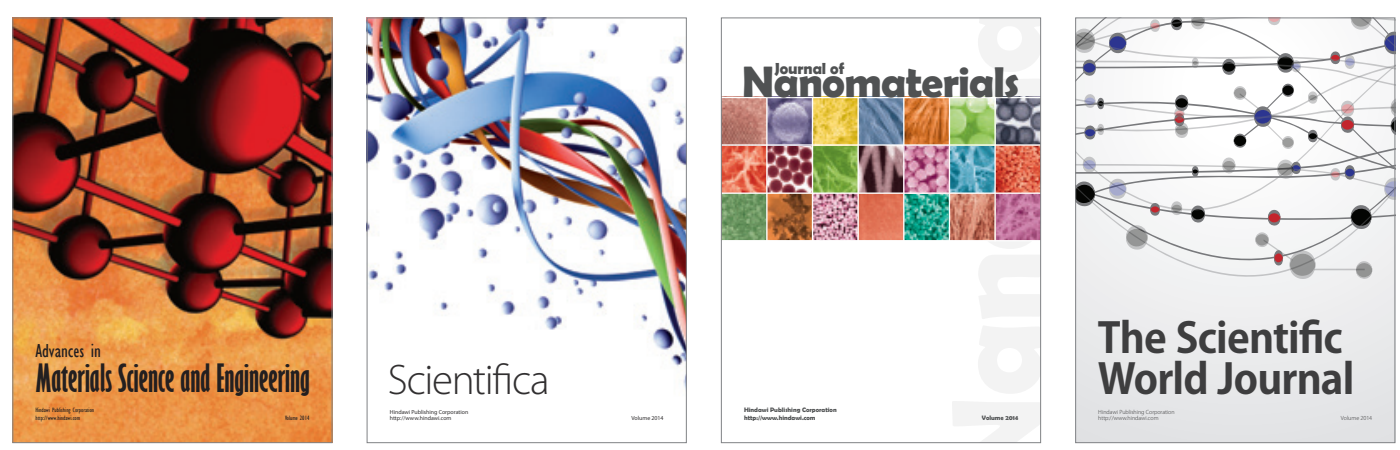

\section{The Scientific World Journal}
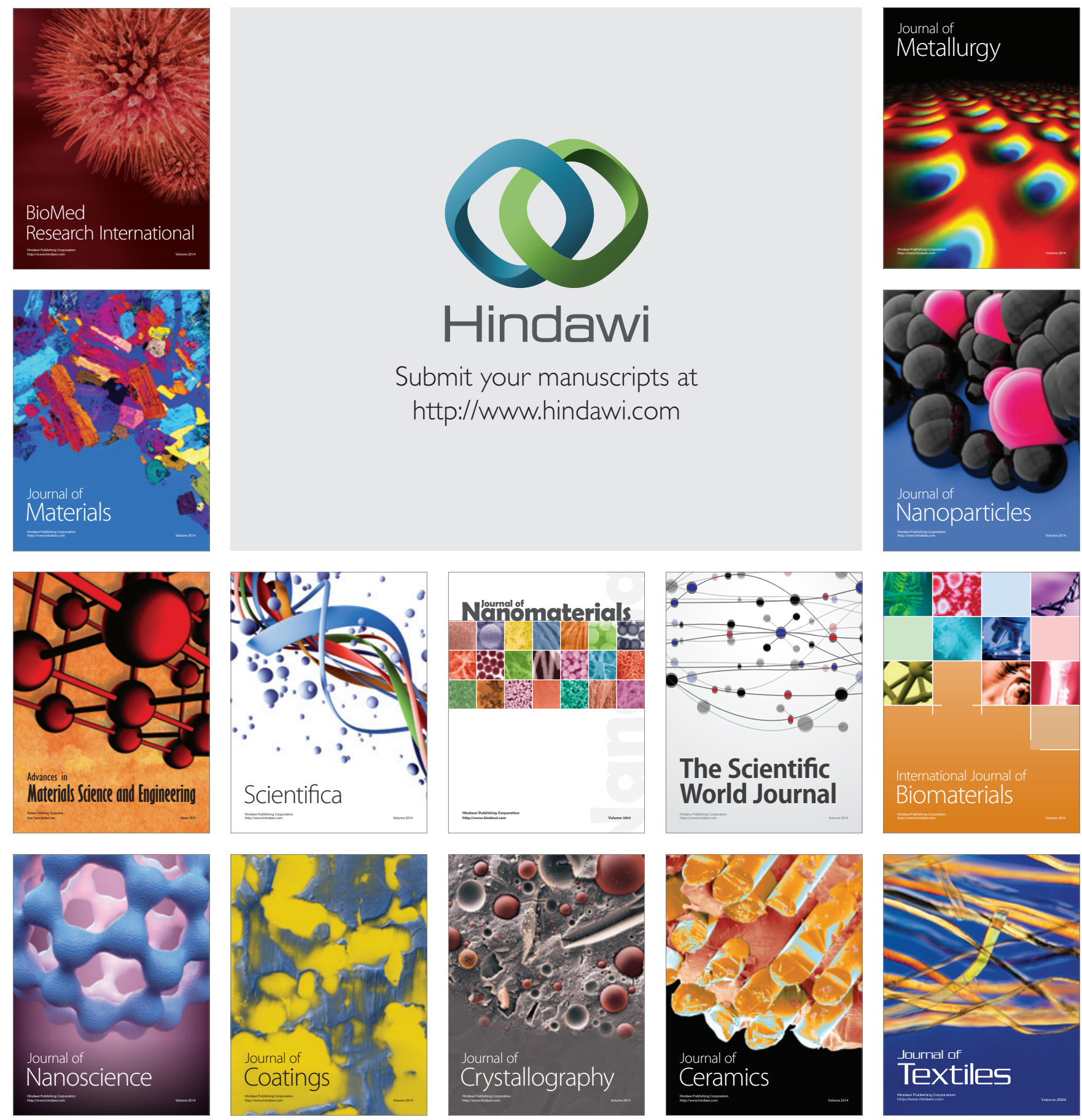